\title{
Exploring the Effects of the Continuation Task on Syntactic Complexity in Second Language Writing
}

\author{
Zhicheng Mao ${ }^{1}$ \& Lin Jiang ${ }^{1}$ \\ ${ }^{1}$ Faculty of English Language \& Culture, Guangdong University of Foreign Studies, Guangzhou, China \\ Correspondence: Lin Jiang, Faculty of English Language \& Culture, Guangdong University of Foreign Studies, \\ Guangzhou, 510420, China. E-mail: jlin@gdufs.edu.cn
}

Received: June 14, 2017 Accepted: July 12, 2017 Online Published: July 13, 2017

doi: 10.5539/elt.v10n8p URL: http://doi.org/10.5539/elt.v10n8p100

\begin{abstract}
This paper aims to investigate the effects of the alignment entailed in the continuation task on syntactic complexity in L2 written production. A total number of 48 sophomores majoring in English at a university in China were randomly assigned to two groups, one is the continuation group and the other is the topic writing group. The current study employs an advanced computational tool 'the L2 Syntactic Complexity Analyser' to assess syntactic complexity in writing samples and focused on 7 indexes including three measures of length of production, two coordinate phrase measures, and two complex nominal measures. The result shows that significant differences exist in six of the syntactic complexity measures with the continuation group outperforming the topic writing group. It is demonstrated that the continuation task, which couples production with comprehension and entails the alignment effect, has a facilitating impact on improving the writing syntactic complexity for L2 learners. The implications of these findings for second language acquisition and L2 writing pedagogy are considered.
\end{abstract}

Keywords: the continuation task, alignment, syntactic complexity, L2 writing

\section{Introduction}

Over the past decades, the study of syntactic complexity in learners' written production has attracted increasing interests from both second language acquisition (SLA) and second language (L2) writing researchers, as evidenced in a voluminous body of research that has explored the relationship between syntactic complexity and L2 proficiency (e.g., Ai \& Lu, 2013; Lu, 2011, 2015; Ortega, 2015; Wolfe-Quintero, Inagaki, \& Kim, 1998; Youn, 2015).

In the previous studies, a wide range of indexes have been used to measure syntactic complexity (see, e.g., Ortega, 2003; Wolfe-Quintero et al., 1998). However, one common limitation of these studies is that relatively a small amount of data was collected due to the lack of advanced computational tools and the demerits of the time-consuming manual analysis. Norris and Ortega (2009) proposed that researchers need to generalize the construct of syntactic complexity and incorporate measures for some syntactic complexity dimensions. To fill this gap, Professor Xiaofei Lu at the Pennsylvania State University developed a computational tool 'the L2 Syntactic Complexity Analyzer' (L2SCA) to analyze the syntactic complexity of English writing. This automatic analyzer draws upon 14 different measures covering length of production units, amounts of coordination, amounts of subordination, degree of phrasal sophistication and overall sentence complexity, which is an advanced indicator of syntactic complexity of writing samples and provides an opening for closer scrutiny in English writing texts.

Previous research demonstrates that there exists significant difference in syntactic complexity in non-native speaker (NNS) and native-speaker (NS) writing (e.g., Ai \& Lu, 2013; Lu \& Ai, 2015), and increasing attention has been given to the development of syntactic complexity in writing (e.g. Ortega, 2015; Zheng \& Feng, 2017). To find a better pedagogy to enhance the syntactic complexity patterns and improve the English proficiency is conductive to the research of SLA and L2 writing.

More recently, the utility of a new type of writing practice 'the continuation task' has been empirically tested. "The continuation task provides learners with a text with its ending removed and requires them to complete it through writing in a most coherent and logical way" (Jiang \& Xu, 2016, p. 133). This dovetails with the 
principles of alignment in language use (Pickering \& Garrod, 2004; Atkinson et al., 2007; Costa et al., 2008). The notion of alignment generally refers to a socio-cognitive process in which human beings engage in coordinated interaction and dynamically adapt to each other. It takes place not only between humans' communicative interaction, but also between human beings and their social and physical environments (Atkinson et al., 2007). To translate the alignment into L2 writing research, C. Wang and M. Wang (2015) designed the continuation task, claiming that the continuation task which couples writing with reading and entails alignment, significantly affects learners' $\mathrm{L} 2$ production. The extant research on the continuation task has mainly focused on the alignment it involves (e.g., C. Wang \& M. Wang, 2015; Xiao, 2013; Xue, 2013), whereas the potential of the continuation task for L2 writing development still needs further exploration.

The present study seeks to examine the effects of the continuation task on syntactic complexity in L2 writing. Our primary focus here is to examine the effects of the alignment (entailed in the continuation task) and to what extent can the continuation task contribute to facilitating syntactic complexity in L2 writing. The results from this empirical study will then be discussed, followed by the implications of our results for SLA and L2 writing pedagogy.

\section{Literature Review}

\subsection{Studies on Syntactic Complexity}

In the early studies, Wolfe-Qunitero el al. (1998) referred to the syntactic complexity in L2 writing as the number of production units, as well as the variety of both basic and sophisticated structures presented in written production. He contends that a lack of complexity means that only a narrow range of basic structures are available or can be assessed. In the latter sense, Ortega (2003) developed the notion of "syntactic complexity" (or linguistic complexity) as "the range of forms that surface in language production and the degree of sophistication of such forms" (p. 492). In this sense, syntactic complexity means various syntactic structures and different patterns embedded in sentences or utterances.

To date, a number of studies have compared the syntactic complexity in the writing of English native speakers (NS) and English as a foreign language (EFL) learners. For example, Lu and Ai (2015) reported the results of a corpus-based comparison of 200 argumentative essays written by NS and 1400 argumentative essays produced by ESL learners. This study employed a computational tool to assess syntactic complexity and found that the EFL group showed greatly varied patterns of difference from the NS group, especially lying in one length of production unit measure (mean length of clause) and two phrasal sophistication measures (complex nominals per clause and per T-unit). Ai and $\mathrm{Lu}$ (2013) examined the difference of syntactic complexity in NS writing and L2 learners of L1 Chinese backgrounds. In this study, 600 essays were collected and analyzed. Results suggested that the two groups differed significantly with respect to length of production unit, amount of subordination, amount of coordination, and degree of phrasal sophistication. Xu et al. (2013) explored the differences in syntactic complexity and syntactic structures between writings of NS and Chinese EFL learners. The results revealed that the increase of the length and embeddedness indexes had obviously a positive correlation with the English proficiency. Besides, the EFL group produced significantly lower length indexes and lower passive and reduced structures.

In addition, Sadri and De Jong (2015) investigated the effects of syntactic complexity on speaking fluency. Thirty Dutch students of an advanced level of English participated in this study and performed two speaking experiments, one in Dutch (L1) and the other in English. The author manipulated syntactic complexity by eliciting active and passive sentences in the experiments. Their study indicates that syntactic complexity has an effect on oral fluency, demonstrated in the hesitations elicited in both L1 and L2, although articulation rate was not affected by syntactic complexity.

Zheng and Feng (2017) carried on a longitudinal study based on the Dynamic Systems Theory to investigate Chinese EFL learners' syntactic complexity development. Aided by the corpus analyzer and dynamic system theory techniques, this study demonstrates that the componential elements within the syntactic complexity subsystem were highly correlated but developed with individual variability.

To sum up, the previous studies examined the variables which may lead to changes in syntactic complexity, such as first language influence, English proficiency. However, no work has been done to investigate whether the alignment entailed in the continuation task has a role to play in the syntactic complexity development of L2 learners. As the interests in studying the syntactic complexity in writing grow recently, this new direction may contribute to the expansion for the research domain. 


\subsection{Studies on the Continuation Task}

As a new writing pedagogy, the continuation task has aroused great interests of both L2 researchers and practitioners. Much of the research on the continuation task has focused on the alignment effect it entails. Wang and Wang (2015) investigated to what extent L2 learners aligned with the input materials in the continuation task and how L2 writing was affected by the alignment effect. In their study, 48 EFL learners were divided into two groups and were asked to continue two stories in Chinese and English version respectively. Study suggested that learners continuing the English-version story made significantly fewer errors than those did the Chinese-version task, which verified the entailment of alignment in the continuation task. Besides, a good number studies have investigated how the alignment in the continuation task manipulates, such as alignment effects in the translation continuation task (Xu, 2016), effect of alignment on text cohesion (Jiang, 2016), and effects of alignment in the continuation task on L2 Chinese writing (Wang, 2016).

A limited number of studies have explored the potential of the continuation task for L2 development: effects of the continuation task on written accuracy, complexity and fluency (Jiang \& Chen, 2015), effects of the continuation task on L2 vocabulary learning (Jiang \& Tu, 2016). The study by Jiang and Chen (2015) compared the learners' written accuracy, complexity, and fluency of the continuation group and the control group. The results revealed that the two groups showed no significant difference on the development of fluency but the continuation group generated more gains on accuracy and complexity than the topic writing task. The study by Jiang and $\mathrm{Tu}$ (2016) discussed the effectiveness of the continuation task on L2 vocabulary learning. A continuation group and a summary-writing group were required to read a passage and complete a writing task by using 12 given words. Researchers found that the continuation group outperformed the summary-writing group in learning L2 vocabulary, specifically in the acquisition of the meaning and use.

In summary, empirical research has afforded some supporting evidence that the continuation task is capable of enhancing language learning efficiency, which points to a new direction for L2 writing and SLA research. The present study investigates whether the continuation task could serve as a new and effective approach to the improvement of syntactic complexity in L2 written production.

\section{Research Procedure}

\subsection{Research Questions}

Given the rationale of the continuation task, I assumed that the continuation task, which entails alignment and affects L2 production, can facilitate the syntactic complexity in L2 writing. With this assumption, this study aims to answer the following two research questions:

1) Does the continuation task have an impact on the syntactic complexity in L2 writing?

2) To what extent does the continuation task influence L2 learners' writing in terms of syntactic complexity?

\subsection{Research Design and Participants}

The study involved 48 sophomores majoring in English at a university in China. These students enrolled in two intermediate English writing classes and were randomly assigned to two groups with 24 students respectively, one is the continuation group and the other is the control group. The mean scores showed no significant group differences in the pretest, namely a free writing task $(t=.720, \mathrm{p}>.05)$.

Both the two groups participated in three treatment sessions between the pretest and posttest. During the entire span of the treatment, the control group was given an assignment of a topic writing task (an English argumentation). For the continuation group, the students were assigned to finish the continuation task, that is, to read an incomplete English argumentation and then write the following part. Two weeks after the treatment section, the posttest was completed to detect the differences in writing performance between the two groups (see Figure 1). 


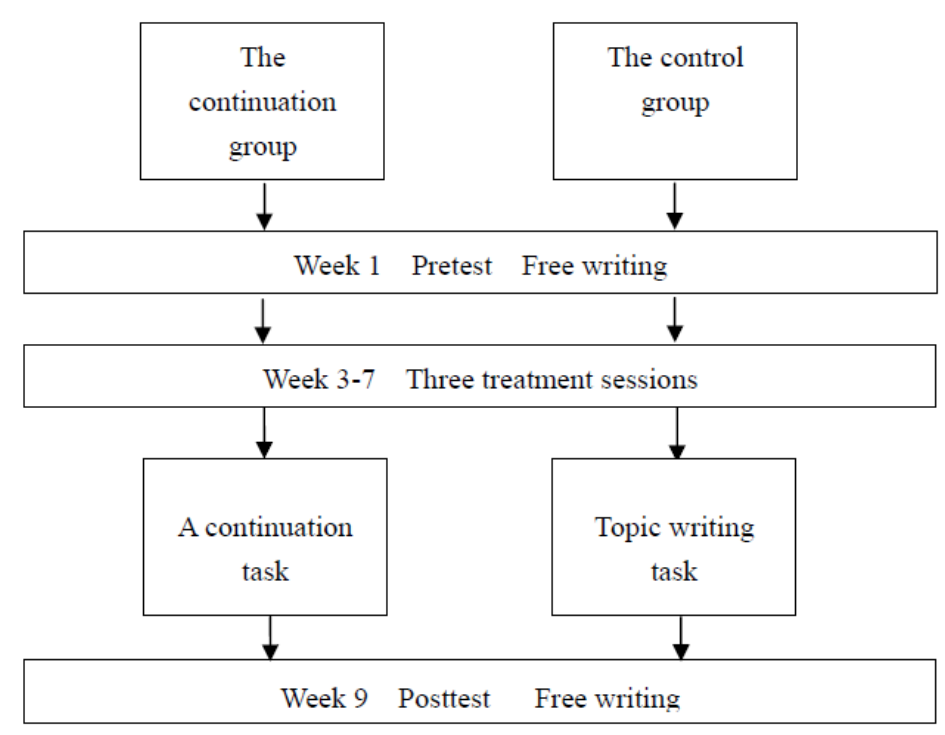

Figure 1. Research design

\subsection{Instruments}

\subsubsection{Writing Tasks}

The participants attended treatment every other week. During each session, the control group was instructed to finish a topic writing task. For the continuation group, students were asked to read the passage provided first, and then continue the essay to complete it. They were encouraged to refer to content, organization, and language from the passage appropriately. The topics for the two groups were closely-related, and students of both groups were expected to write a minimum of 350 words in each treatment.

\subsubsection{Reading Materials}

Three topics for treatment task which could effectively evoke students' interests and help to arouse their desires to write were selected. The topics were: McDonald's or High-end Restaurant, The Popular TV Shows and The Stresses of Being a Celebrity. For the control group, an instruction was given with no other materials offered. For the continuation group, an essay of English native speakers was provided with its ending removed. An overview of the topics and the length of the materials are listed in Table 1.

Table 1. Topics for the treatments

\begin{tabular}{lll}
\hline & Topics for the control group & Topics for continuation task group \\
\hline Treatment 1 & McDonald's or High-end Restaurant? & $\begin{array}{l}\text { A vote for McDonald's } \\
\text { (426 words) }\end{array}$ \\
Treatment 2 & The Most Popular TV Shows & $\begin{array}{l}\text { The Most Popular TV Shows } \\
\text { (399 words) }\end{array}$ \\
Treatment 3 & The Stresses of Being a Celebrity & The Stresses of Being a Celebrity \\
& & $(325$ words $)$ \\
\hline
\end{tabular}

\subsubsection{Teachers' Assessment}

After each test, students' essays were scoring using an analytic rating scale borrowed from 2016 National English Writing Contest (NEWC) held by Foreign Language Teaching and Research Press in China. The ratings consisted of assessments on content, organization and language, counting $40 \%, 30 \%$ and $30 \%$ of the total points respectively. The inter-rater reliability for scoring the essays reached .91 and all the disagreements were resolved through negotiation and by consulting native speakers. 


\subsection{Data Analysis}

After the third treatment, a posttest was conducted two weeks apart. With regard to the posttest, two groups were required to do a free writing of a report. Each student was to choose one hot spot of society and write an argumentative essay containing at least 250 words from a specific perspective. The posttest was completed in class within 35 minutes and the texts were collected and then transcribed for further analysis.

The current study employs L2SCA designed by $\mathrm{Lu}$ (2010) and will focus on 7 indexes that are included in this automatic analyzer (see Table 2). These include three measures of length of production: MLC, MLS, and MLT; two coordinate phrase measures, $\mathrm{CP} / \mathrm{C}$ and $\mathrm{CP} / \mathrm{T}$; and two complex nominal measures, $\mathrm{CN} / \mathrm{C}$ and $\mathrm{CN} / \mathrm{T}$. We select these because the seven indexes show significant positive changes from lower to higher levels (Lu, 2011). In this study, Lu analyzed 3,678 essays from a corpus to investigate the relationship between syntactic complexity and language development and detect these 7 indexes progress linearly across English levels.

Table 2. Syntactic complexity measures evaluated

\begin{tabular}{lll}
\hline Measure & Code & Formula \\
\hline $\begin{array}{l}\text { Length of production unit } \\
\text { Mean length of clause }\end{array}$ & MLC & \# of words/\# of clauses \\
$\begin{array}{l}\text { Mean length of sentence } \\
\text { Mean length of T-unit }\end{array}$ & MLS & \# of words/\# of sentences \\
Amount of coordination & MLT & of words/\# of T-units \\
Coordinate phrases per clause & $\mathrm{CP} / \mathrm{C}$ & \# of coordinate phrases/\# of clauses \\
$\begin{array}{l}\text { Coordinate phrases per T-unit } \\
\text { Degree of phrasal sophistication }\end{array}$ & $\mathrm{CP} / \mathrm{T}$ & \# of coordinate phrases/\# of T-units \\
Complex nominals per clause & & \\
Complex nominals per T-unit & $\mathrm{CN} / \mathrm{C}$ & \# of complex nominals/\# of clauses \\
\hline
\end{tabular}

\section{Results}

The independent samples t-tests were then conducted on the selected L2SCA indexes to examine if significant differences in syntactic complexity measures existed between the continuation group and the control group. The descriptive statistics for the seven measures are displayed in Table 3. It is shown that six indexes of the continuation group are significantly higher scores than those of the control group: MLC $(t=2.404, p<0.05)$, MLS $(\mathrm{t}=2.735, \mathrm{p}=0.001), \operatorname{MLT}(\mathrm{t}=2.494, \mathrm{p}<0.05), \mathrm{CP} / \mathrm{T}(\mathrm{t}=3.341, \mathrm{p}<0.05), \mathrm{CN} / \mathrm{C}(\mathrm{t}=2.418, \mathrm{p}<0.05)$ and $\mathrm{CN} / \mathrm{T}(\mathrm{t}=3.341$, $\mathrm{p}<0.05)$, however, no significant difference was found in $\mathrm{CP} / \mathrm{C}(\mathrm{t}=1.92, \mathrm{p}=0.061)$. We can conclude that students in the continuation group have made great progress in their writing during the treatment session, resulting in a significant increase in the six indices which are positively related to English proficiency. These findings support our prediction that the continuation task may have a beneficial effect on syntactic complexity in L2 writing.

Table 3. Descriptive statistics for seven measures

\begin{tabular}{lllll}
\hline \multirow{2}{*}{ Group } & \multicolumn{2}{l}{ Continuation Group } & \multicolumn{2}{l}{ Control Group } \\
\cline { 2 - 5 } & $M$ & $S D$ & $M$ & $S D$ \\
\hline Mean length of clause (MLC) & 10.937 & 2.761 & 9.448 & 1.244 \\
Mean length of sentence (MLS) & 25.238 & 8.545 & 18.682 & 2.425 \\
Mean length of T-unit (MLT) & 20.846 & 5.177 & 17.456 & 2.539 \\
Coordinate phrases per clause (CP/C) & .277 & .145 & .213 & .072 \\
Coordinate phrases per T-unit (CP/T) & .595 & .336 & .396 & .145 \\
Complex nominals per clause (CN/C) & 1.558 & .307 & 1.356 & .27 \\
Complex nominals per T-unit (CN/T) & 3.406 & 1.182 & 2.513 & .562 \\
\hline
\end{tabular}




\section{Discussion and Conclusions}

The results above show that the continuation task has a facilitating impact on the syntactic complexity in L2 writing, especially in terms of the length of production unit and the degree of phrasal sophistication. This demonstrates that the continuation task outperforms the topic writing task in the development of syntactic complexity and thus improves the English proficiency for L2 learners, which is consistent with the finding of Wang \& Wang (2015) that the alignment (entailed in the continuation task) can significantly affect L2 production and is capable of facilitating L2 learning.

The alignment effect of the continuation task comes about largely due to the intimate coupling of production with comprehension. In effect, this coupling reinforces input/output coordination, creates communicative needs, motivates mindreading, enables learners to discern communicative intentions of the text writer, and forces interaction between the text and the learner (C. Wang \& M. Wang, 2015). It may facilitate syntactic complexity in $\mathrm{L} 2$ production from several aspects.

Firstly, the continuation task requires learners to write the rest part to align with the input given, which enables them to attend to the input they receive and notice the gap between their current English proficiency and the reading materials. Since the language and structure are exquisite in the input, students try to modify their language and structure so that the written context would not be discordant. On the other hand, since no reading materials is provided in the topic writing task, students tend to allocate more time to create the contents and focus on accuracy rather than modifying the language, which supports Skehan's trade-off effect that a competition for attentional resources among accuracy, fluency and complexity (Skehan, 1998).

Secondly, the coupling of content-creating and language-imitating provides learners with better conditions to modify their output and integrate new uses of linguistic items. In order to write coherently, learners try to use relatively complicated structures which are beyond their current proficiency. As the learners summarize the rules of the complicated structures and have a deeper understanding, the linguistic items are consolidated and preserved in the working memory. However, learners who were assigned the topic writing task could avoid using the difficult structures and use simple sentences instead, since the topic writing task doesn't demand for relatively strong language competence. From a long-term point of view, the topic writing task might not exert a positive effect on the development of syntactic complexity.

Finally, one limitation of this study is the samples of the texts. All the written samples were produced by L1 Chinese learners of intermediate English levels only. As for the additional study, learners of different English proficiency and different L1 backgrounds can be taken into consideration. We believe that such research could expand our understanding of L2 writing development and it may be of potential interest not only to SLA researchers but also to $\mathrm{L} 2$ teachers.

To sum up, this study points to the significance for L2 writing and SLA researchers to be aware of the role that the alignment plays in L2 writing. A solid understanding of the effects of the continuation task on syntactic complexity would have important implications for how the alignment influences learner's writing and help to develop appropriate pedagogical tasks for L2 learners.

\section{Acknowledgements}

This research was supported by a grant from the China National Social Science Foundation (14CYY018).

\section{References}

Ai, H., \& Lu, X. (2013). A corpus-based comparison of syntactic complexity in nns and ns university students writing. In A. Díaz-Negrillo, N. Ballier, \& P. Thompson (Eds.), Automatic treatment and analysis of learner corpus data (pp. 249-264). Amsterdam: John Benjamins. https://doi.org/10.1075/scl.59.15ai

Atkinson, D., Nishino, T., Churchill, E., \& Okada, H. (2007). Alignment and interaction in a sociocognitive approach to second language acquisition. The Modern Language Journal, 91, 169-188. https://doi.org/10.1111/j.1540-4781.2007.00539.x

Crossley, S. \& D. McNamara. (2014). Does writing development equal writing quality? A computational investigation of syntactic complexity in L2 learner. Journal of Second Language Writing, 26, 66-79. https://doi.org/10.1016/j.jslw.2014.09.006

$\mathrm{Lu}, \mathrm{X}$. (2010). Automatic analysis of syntactic complexity in second language writing. International Journal of Corpus Linguistics, 15, 474-496. https://doi.org/10.1075/ijcl.15.4.02lu

$\mathrm{Lu}, \mathrm{X}$. (2011). A corpus-based evaluation of syntactic complexity measures as indexes of college-level ESL writers' language development. TESOL Quarterly, 45, 36-62. https://doi.org/10.5054/tq.2011.240859 
Lu, X. (2014). Computational Methods for Corpus Annotation and Analysis. Dordrecht: Springer. https://doi.org/10.1007/978-94-017-8645-4

$\mathrm{Lu}, \mathrm{X}, \& \mathrm{Ai}, \mathrm{H}$. (2015). Syntactic complexity in college-level English writing: Differences among writers with diverse L1 backgrounds. Journal of Second Language Writing, 29, 16-27. https://doi.org/10.1016/j.jslw.2015.06.003

Jiang, L., \& Chen, J. (2015). The continuation task: Effects on written accuracy, complexity and fluency. Modern Foreign Languages, 38, 366-375.

Jiang L, \& Xu X. (2016). Effect of Alignment on Text Cohesion in the Continuation Task. English Language Teaching, 10, 133-141. https://doi.org/10.5539/elt.v9n10p133

Ortega, L. (2000). Understanding syntactic complexity: The measurement of change in the syntax of instructed L2 Spanish learners. Unpublished doctoral dissertation. Honolulu: University of Hawaii.

Ortega, L. (2003). Syntactic complexity measures and their relationship to L2 proficiency: A research synthesis of college-level L2 writing. Applied Linguistics, 24, 492-518. https://doi.org/10.5539/elt.v9n10p133

Ortega, L. (2015). Syntactic complexity in L2 writing: Progress and expansion. Journal of Second Language Writing, 29, 82-94. https://doi.org/10.1016/j.jslw.2015.06.008

Pickering, M. J., \& Garrod, S. (2004). Toward a mechanistic psychology of dialogue. Behavioral and Brain Sciences, 27, 169-190. https://doi.org/10.1017/S0140525X04000056

Sadri Mirdamadi F, De Jong NH. (2015). The effect of syntactic complexity on fluency: Comparing actives and passives in L1 and L2 speech. Second Language Research, 31(1), 105-116. https://doi.org/10.1177/0267658314554498

Skehan, P. (1998). A Cognitive Approach to Language Learning. Oxford: Oxford University Press.

Wang, C. (2012). The continuation task - an effective way to facilitate L2 learning. Foreign Language World, 5 , 2-7.

Wang, C, \& Wang, M. (2015). Effect of alignment on L2 Written Production. Applied Linguistics, 5, 503-526.

Wolfe-Quintero, K., Inagaki, S., \& Kim, H.-Y. (1998). Second language development in writing: Measures of fluency, accuracy and complexity. Honolulu: University of Hawaii, Second Language Teaching and Curriculum Center.

Xiao, T. (2013). The effect of alignment on L2 writing accuracy. MA Thesis. Guangzhou: Guangdong University of Foreign Studies.

Xu, X. et al. (2013). A study on the syntactic complexity of English essays written by Chinese students of English, Foreign Language Teaching and Research, 2, 264-275.

Xue, H. (2013) Interest-related alignment in L2 story continuation. MA Thesis. Guangzhou: Guangdong University of Foreign Studies.

Youn. S. J. (2014). Measuring syntactic complexity in L2 pragmatic production: Investigating relationships among pragmatics, grammar, and proficiency. System, 42, 270-287. https://doi.org/10.1016/j.system.2013.12.008

Zheng, Y. \& Feng, Y. (2017). A Dynamic Systems study on Chinese EFL learners' syntactic and lexical complexity development. Modern Foreign Languages, 1, 57-68.

\section{Copyrights}

Copyright for this article is retained by the author(s), with first publication rights granted to the journal.

This is an open-access article distributed under the terms and conditions of the Creative Commons Attribution license (http://creativecommons.org/licenses/by/4.0/). 